\title{
A Case Study in Crisis Management in the Digital Transformation Era: Wells Fargo \& Company
}

\author{
Wenjing Wang and Arthur S. Guarino
}

\section{ABSTRACT}

\begin{abstract}
This case study deals with one of the biggest financial scandals in the new millennium among the banking sector in which the banking giant, Wells Fargo \& Company (WFC), has opened millions of accounts without acknowledging its customers. It has been charging various fees without the consent of the company's existing clients, and it has involved many people with the personal credit crisis. On the contrary, senior management team was rewarded enormously for the rocketing profits resulting from the phony accounts numerous fees and elevated the bank's share price in a relatively short time. After the accounts scandal was unveiled by its employees and reported by the media, Wells Fargo's reputation was in great danger. While reputation is vital for almost all companies, it is especially essential for the financial services industry, where reputation is a deep-rooted culture. Crisis management strategies in the new era of digital transformation for companies like Wells Fargo as well as other financial services companies are crucial. Risk management is essential in today's business world, but crisis management as contingent plans cannot be ignored since events are not always going as many think they would be.
\end{abstract}

Keywords: Crisis management, Digital transformation, Reputation, Wells Fargo.

\author{
Submitted : June 07, 2021 \\ Published : July 20, 2021 \\ ISSN: $2507-1076$ \\ DOI: $10.24018 / \mathrm{ejbmr} .2021 .6 .4 .911$ \\ Wenjing Wang, MSF \\ Zhejiang Business College, China. \\ (e-mail: 00570@zjbc.edu.cn) \\ Arthur S. Guarino, MBA, MSSC, JD* \\ Rutgers University, Newark NJ, USA. \\ (e-mail: artiesg @ business.rutgers.edu)
}

*Corresponding Author

\section{INTRODUCTION}

An important asset for any business, whether large, midsize, or small, is its reputation. It has been stated that regardless of the revenues, net profits, or market share a company has, its reputation is vital if it is to thrive and survive in any competitive environment. Once that reputation is gone due to scandal, it is tough to regain and sometimes can lead to the company's downfall. Loss of reputation damage to a financial institution will ultimately lead to loss of jobs, a decline in the shareholder's investment in the company, and the creditor's loss of principal and interest in loans to the firm.

In today's digitized world, a financial company must not only be able to maintain its reputation but also deal with a crisis that could severely impact its future and standing in its industry. The digital age has allowed financial companies to not only minimize their risk but also enjoy the opportunity to achieve better returns, increased net profits, and higher revenues. But the digital age also means that bad news about a financial company can travel faster than ever before, which could hurt the company's stock price on the financial markets and cause shareholders to lose a substantial part of their investment. The United States has seen its share of financial sector scandals through the years, but with the advent of the digital age, bad news about a financial company travels faster and further than ever before. The Wells Fargo scandal changed the method in how the bank does business and treats its retail clients. Many analysts are still wondering how this scandal will affect Wells Fargo in the long run.

\section{COMPANY BACKGROUND}

Wells Fargo Bank, established on March 18, 1852, is a San Francisco based commercial bank which has a good reputation for sound management by safeguarding itself through the financial and economic depression of the 1930's and served the United States during World War II. Moreover, it gained enormous trust from prudent management during the 2008-2009 Financial Crisis until the phony accounts scandal came to the forefront of the public eye in September 2016.

\section{CURRENT SITUATION}

WFC's senior management pressured thousands of its employees with unrealistic sales goals from 2002 to 2016 [1]. Chief Executive Officer (CEO) and Chairman John Stumpf in 2010 set overly aggressive sales targets and that WFC's employees needed to live up to their reputation of being the best cross-sellers min the banking industry. Cross-selling refers to signing up existing customers for additional products [9]. As a result of meeting the sales targets, employees were under enormous pressure to open substantial amounts of fraudulent accounts and charge various fees without the consent of the company's existing clients [6]. U.S. federal regulators confirmed that Wells Fargo had opened phony accounts for clients without their permission from 2011 to 2015.

Graham et al. [7] proved that governance practices and financial incentives could reinforce corporate culture. Corporate culture is viewed as one of the three most important 
factors in valuing companies by executives. Nevertheless, they point out that rewards granted to employees to meet a metric without valuing their actions will negatively affect a company's culture. They continue to conclude that institutional culture is set by current CEOs who are elected by the boards. However, John Stumpf's over-powering leadership in holding CEO and Chairman's dual positions, along with WFC's compensation scheme, has greatly incentivized him to push up earnings without legal and ethical hesitations. What WFC did in the account scam is exactly the opposite to WFC's stated vision and values: "Our vision has nothing to do with transactions, pushing products, or getting bigger for the sake of bigness. It is about building lifelong relationships one customer at a time. ... We strive to be recognized by our stakeholders as setting the standard among the world's great companies for integrity and principled performance. This is more than just doing the right thing. We also have to do it in the right way."

Glazer [5] reports that John Stumpf was awarded a \$19.3 million compensation package in 2014. This compensation package consisted of $\$ 2.8$ million in base pay, $\$ 12.5$ million of WFC's shares as a bonus which is mostly tied to the company's performance, and a $\$ 4$ million cash bonus. He was compensated the same amount in 2013, and \$22.9 million in 2012. John Stumpf's 2012's payment package made him the highest-paid CEO in the banking sector that year. His 2014 compensation package was second to Goldman Sach's CEO Lloyd Blankfein's as the most extensive pay package among banking sector executives.

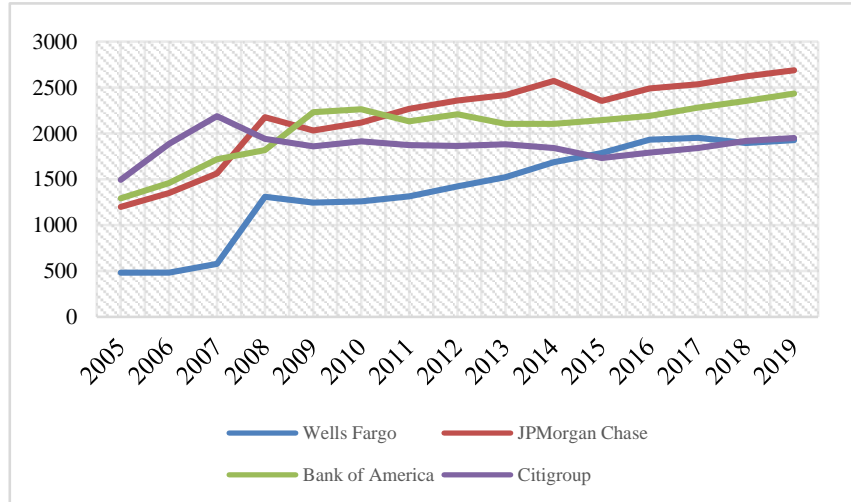

Fig. 1. Total asset changes of Wells Fargo, JPMorgan Chase, Bank of America, Citigroup in billion US dollars from 12/31/2005 to 12/31/2019. Data source: macrotrends.

In 2015, WFC hit a record high in market capitalization of approximately $\$ 287.9$ billion before its account fraud scandal became public in 2016. According to Figure 1, its total assets in 2015 was $\$ 1787.632$ billion, surpassing Citigroup (\$1731.21 billion), ranked third for the first time since 2005 in being among the largest four banks in the United States. The other two were JPMorgan Chase (\$2351.698 billion) and Bank of America (\$2144.287 billion). WFC's capital expansion started in 2007, and before this year, its total assets were far behind the other three banks. The 2008-2009 Financial Crisis slowed down the massive capital expansion slightly due to the dire economic environment. However, its total assets increased steadily from 2009 to 2016.

WFC gained a positive reputation from being among the most prudent and valuable banks in the United States by successfully navigating itself through the 2008-2009 financial tsunami. In contrast, many financial institutions in America and worldwide suffered from severe losses due to the subprime mortgage loan crisis. According to Fig. 2, WFC's counterparties, the other two biggest of the four banks in America, Citigroup, and Bank of America, witnessed dramatic net income losses during the financial recession. Some large financial corporations such as Lehman Brothers, Washington Mutual, and Franklin Bank went bankrupt during the international banking crisis. Unlike most financial firms who took a substantial risk in the toxic subprime mortgage market and reported significant losses in net income afterwards, WFC's ROA rose quickly and steadily after 2008. Despite being the fourth largest bank in America, except for 2013 and in 2014 being the third, its ROA outperformed all other three banks from 2008 to 2017 (Fig. 3). As a result of strong financial figures and indicators under the unethical management administration, WFC outperformed the SPDR S\&P Bank ETF (KBE) significantly and enjoyed an enormous and continuous stock price growth (Fig. 4) starting from the end of 2011 to mid-2015 until WFC was embroiled in generating massive fake accounts and charging excessive unauthorized fees. KBE stands for an American publicly traded fund whose objective is to replicate the performance of S\&P Banks Select Industry Index.

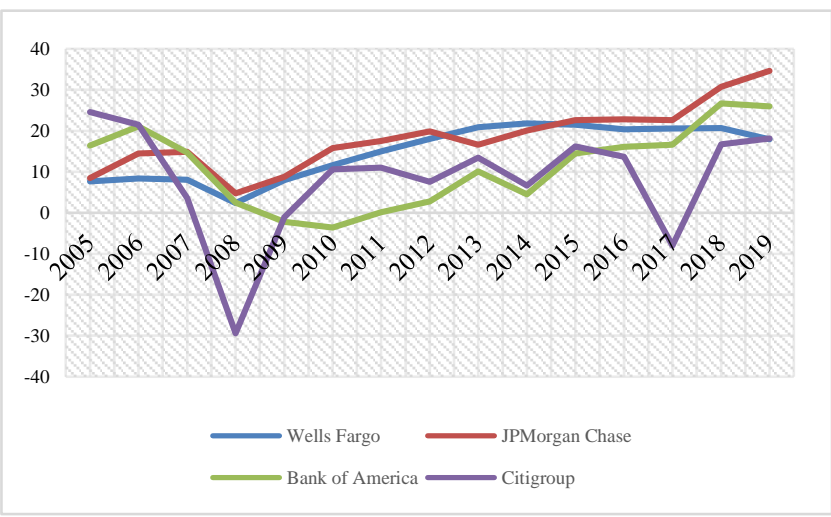

Fig. 2. Net income changes of Wells Fargo, JPMorgan Chase, Bank of America, Citigroup in billion US dollars from 12/31/2005 to 12/31/2019. Data source: macrotrends.

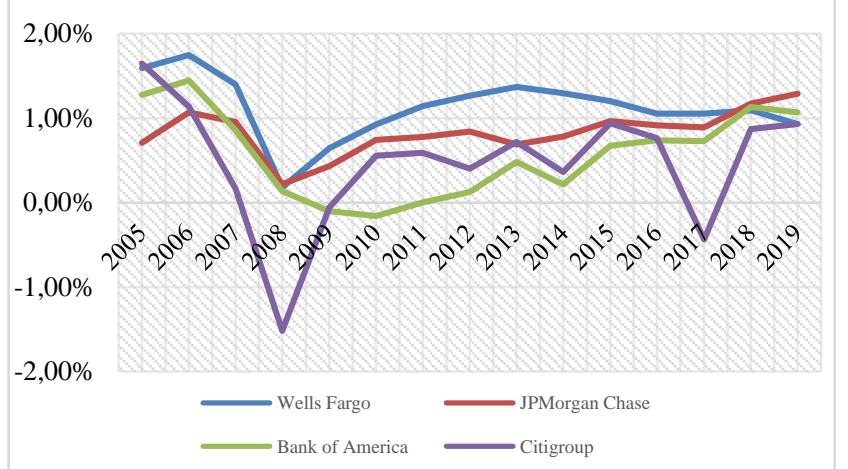

Fig. 3. Return on Assets (ROA) of Wells Fargo, JPMorgan Chase, Bank of America, Citigroup from 12/31/2005 to 12/31/2019. Data source: macrotrends.

Dwyer [8], Tayan [2], and Prentice et al. [3] revealed the timeline of how WFC's account scandal was brought to the public forefront and the settlements WFC made with 
authorities to those victims involved in this criminal act (Fig. 5).

Based upon the scandal timetable displayed in Fig. 5, Fig. 6 depicts the impact on the stock market in conjunction with the illegal sales practices related issues due to an efficient market generated by digital tools. The stock price was fluctuating and kept a downward trend since WFC was involved in class-action lawsuits starting in mid-2015. Its stock price then dropped to the lowest of $\$ 44.28$ per share on September 26, 2016 from a peak of \$57.94 on July 13, 2015. Freed and Dilts [4] analyzed the two hours after John Stumpf announced he would leave his position and the result was that Wall Street witnessed a $2 \%$ rise in WFC's trading price. The stock price then experienced a sharp rise from October 31 , 2016.

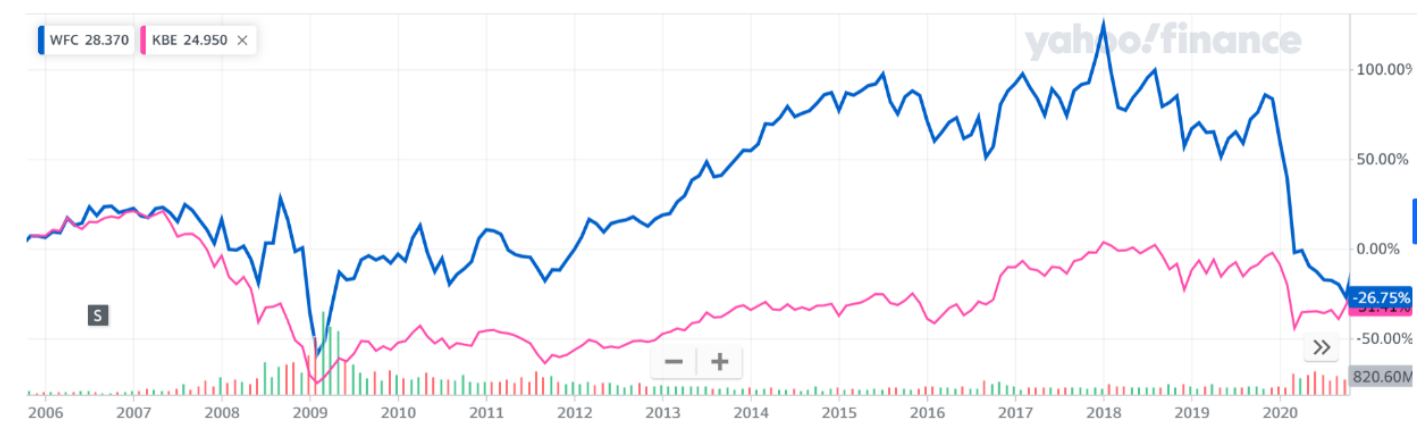

Fig. 4. One-month stock price changes in percentage of Wells Fargo (blue) in comparison with KBE (pink) from Dec. 2005 to Dec. 2020. Source: Yahoo Finance.

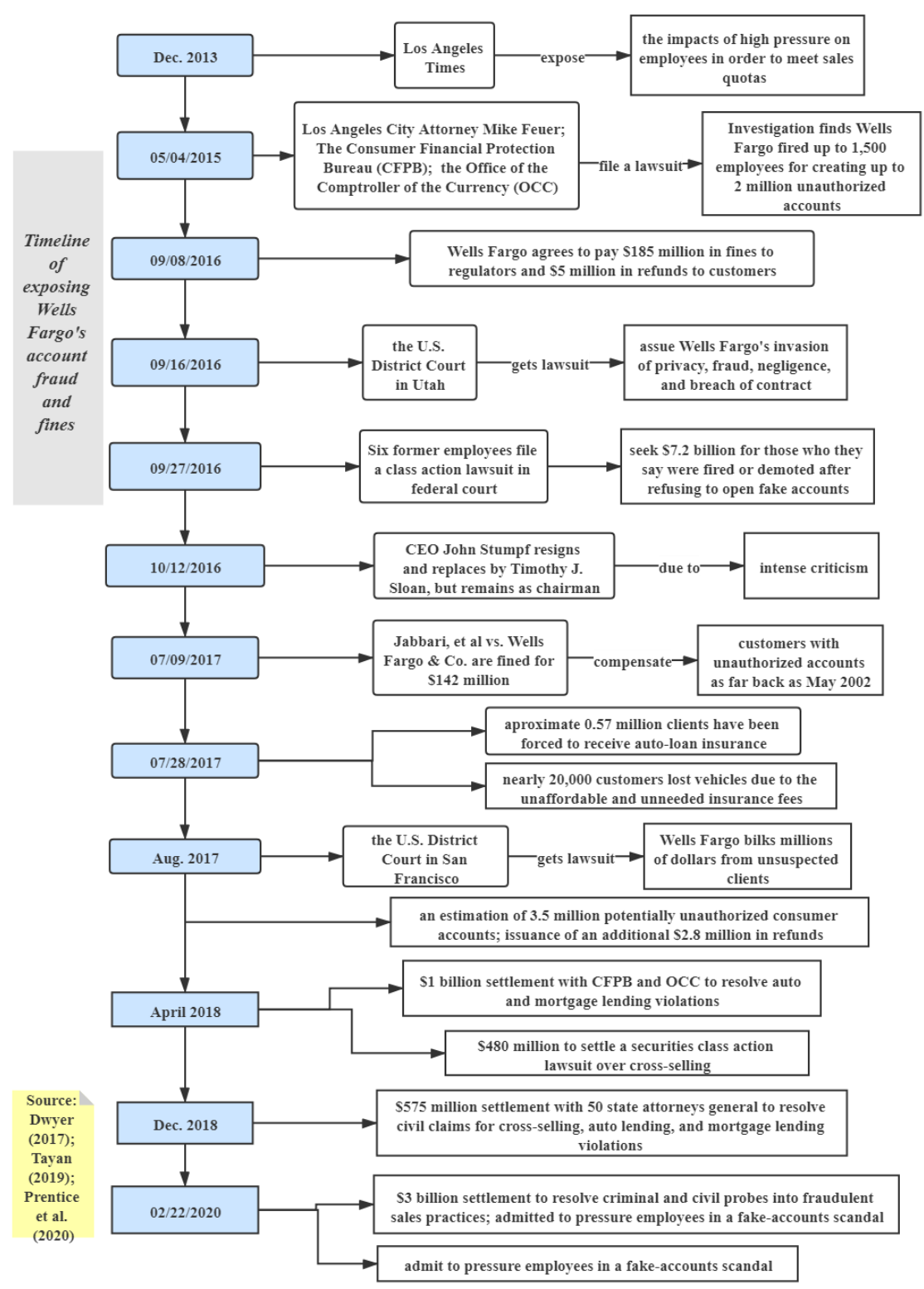

Fig. 5. Timeline of exposing Wells Fargo's account fraud and fines. 


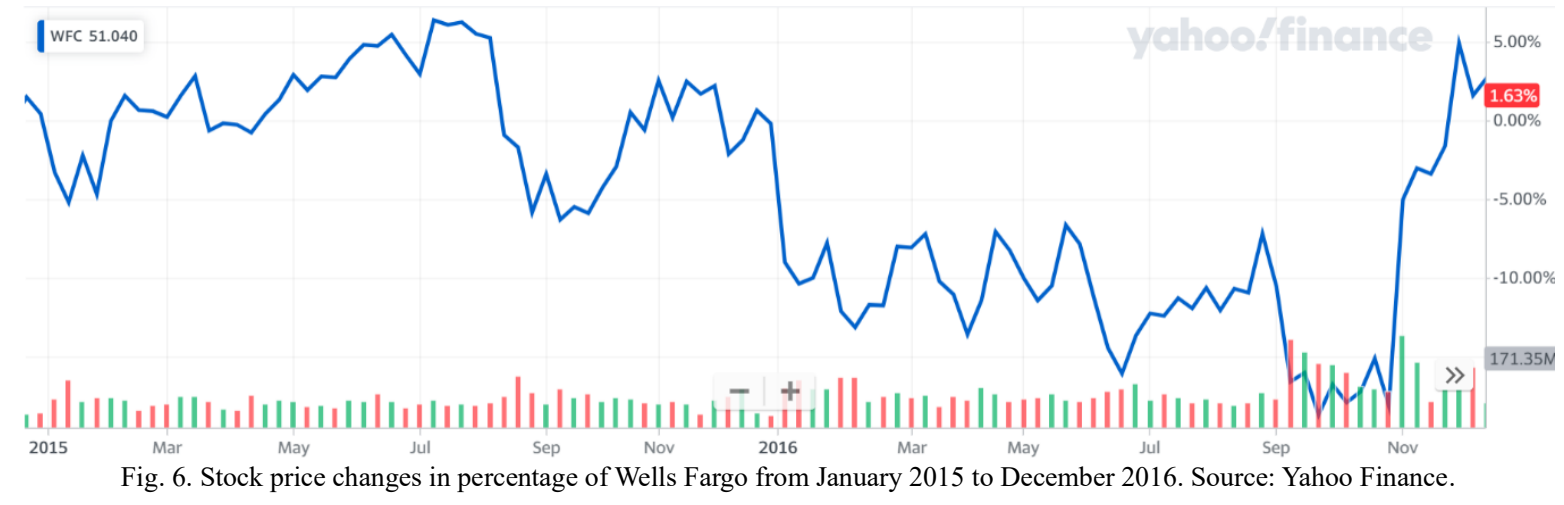

\section{Assignment Memo}

We are becoming very concerned about financial services institutions such as Wells Fargo and their future and how it can gain back trust and reputation from the public after a scandal has occurred in the digital transformation era. Based upon this background information, answer the following questions:

1. The importance of dealing with crisis management in the financial sector in the digitized world.

2. Specify strategic crisis management plans for Wells Fargo which could also be applied to some other financial services corporations.

Your response to this memo includes your answers to the above with supporting research findings or empirical evidence. It is imperative that one can fully understand why you chose your strategies and what you think will be the impact on gaining back reputation in the banking and financial services industry and with clients.

Formulate your reply with your recommendations in two weeks.

\section{CONCLUSION}

Banking giant Wells Fargo has sold financial products to their clients without authorization. It has created 3.5 million unauthorized accounts for its clients just for the sake of making revenues through selling various financial products. Not only did the scandal cost Wells Fargo millions of dollars in legal fees, but also to settle huge class-action lawsuits. Wells Fargo is still in the process of attempting to regain the trust of its clients and that of the general public. When and whether that will ever happen remains to be seen.

\section{REFERENCES}

[1] A. Mallin, and J. Doom. (February 2020). Wells Fargo agrees to \$3 billion settlement over fake accounts. $A B C$ News. [Online]. Available: https://abcnews.go.com/Business/wells-fargo-agrees-billionsettlement-fake-accounts/story.

[2] B. Tayan. (February 2019). The Wells Fargo Cross-Selling Scandal. Harvard Law School Forum on Corporate Governance. [Online]. Available: https://corpgov.law.harvard.edu/2019/02/06/the-wellsfargo-cross-selling-scandal-2/.

[3] C. Prentice, P. Schroeder, and I. Moise. (February 2020). Wells Fargo to pay $\$ 3$ billion to U.S., admits pressuring workers in fake-accounts scandal. $\quad$ Reuters. $\quad$ OOnline]. Available: https://www.reuters.com/article/us-wells-fargo-scandal-deal/wellsfargo-to-pay-3-billion-to-u-s-admits-pressuring-workers-in-fakeaccounts-scandal-id.
[4] D. Freed, and E. Dilts. (October 2016). Wells Fargo CEO John Stumpf quits, replaced by Tim Sloan. yahoo!finance. [Online]. Available: https:/finance.yahoo.com/news/wells-fargo-ceo-john-stumpf003451641.html.

[5] E. Glazer. (March 17, 2015). Wells Fargo CEO John Stumpf's Compensation Flat at \$19.3 Million. The Wall Street Journal. [Online]. Available: $\quad$ https://www.wsj.com/articles/wells-fargo-ceo-johnstumpfs-compensation-flat-at-19-3-million.

[6] J. Venable, "Wells Fargo: Where Did They Go Wrong," Paper, Harvard University, Cambridge, MA, ResearchGate, 2017.

[7] J. R. Graham, J. Grennan, C. R. Harvey, and S. Rajgopal, "Corporate Culture: The Interview Evidence,” Paper, Columbia Business School, New York, NY, No. 16-70, 2016.

[8] K. Dwyer. (August 2, 2017). Timeline: How the Wells Fargo scandals unfolded. The Morning Call. [Online]. Available: https://www.mcall.com/business/mc-biz-wells-fargo-timeline20170802-story.html.

[9] L. J. Lynch, and C. Cutro. (October 27, 2017). The Wells Fargo Banking Scandal. Harvard Business Review. [Online]. Available: https://www.hbsp.harvard.edu/product/UV7267-PDF-ENG.

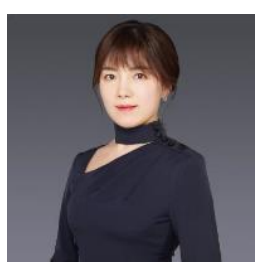

Wenjing Wang is a Finance lecturer in Accounting and Financial Management department at Zhejiang Business College, China. She is also the vicepresident at Zhong Xiang venture capital company with responsibilities of writing due diligence and managing customer relations. Meanwhile, she is an investor who has invested in different projects and gained great insights into the business field.

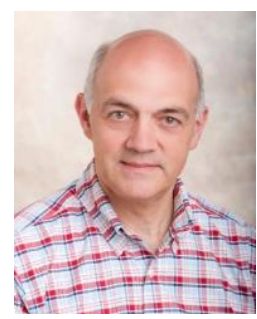

Arthur S. Guarino 's professional career has been deeply involved in the financial services industry with such corporations as TIAA-CREF, Met Life, and The Bank of New York. He has held various positions in the financial services field including sales, training and development, administration, product development, customer service and relationship, and management. His teaching experience as a full-time instructor has been primarily at Stevens Institute of Technology in Hoboken, New Jersey and Rutgers University in Newark, New Jersey. 